\title{
Social Framework of Ecology: Representation of Nature in Folk Tradition and Culture of the tribes in Namphake Village
}

\author{
Prerona Bura Gohain \\ (Student, Department of Geography, Cotton College State University, Guwahati, Assam, India.)
}

\begin{abstract}
North-East India is well known for its ethnic integrity consisting of different tribal groups. Most of the tribes of North-East India have always made a cordial relationship with the nature. There cultures and traditions are very close to nature. One of such tribe is the "Tai- Phake" tribe, which have a population of about 1426 only and Namphake" village has got the highest population concentration of this tribe. This village has been the centre of focus, all over the world for their language, food habits, festivals, housing pattern etc. Though surrounded by modernization, westernization, etc, they have always tried to preserve their age old practices. The influence of Buddhism among them has always helped them to maintain a simple life. So these practices have allowed them to maintain a healthy ecology. This paper is an attempt to analyze the subsistence behavior of the Tai-Phake people in maintaining and preserving their culture and tradition with a strong bonding with their surrounding environment.
\end{abstract}

Key words- Tribes, North- East India, Nature, Cultures and Traditions.

\subsection{Statement of the problem:}

\section{INTRODUCTION}

The Tai-Phake people are a small ethnic tribal group of North-East India. According to the chronicles the Tai-Phakes migrated from Mung-Mau and entered Assam in 1775 A.D during the reign of the Ahom king Lakshmi Sinha (1769- 1780 A.D). They settled at Nangtao of present Arunachal Pradesh and they belong to the great Tai race. Ethnically they belong to the Mongoloid tribe. They settled in Arunachal Pradesh for a few years and during the British rule they gradually entered Assam and permanently settled mostly on the bank of Buridihing(Namhuk) river in the undivided Dibrugarh district scattered in ten villages, namely- Namphake, Tipamphake, Borphake, Munglang, Ningkam, Phaneng, Manmo, Nonglai, Long and Lungkung. Presently they live in nine villages of Dibrugarh and Tinsukia districts which are as follows :- Namphake and Tipamphake on the bank of the river Buridihing of Naharkatiya area of Dibrugarh district, and Munglang, Manmo, Borphake, Man Long or Longphake, Ningam Phake or Ningkam, Nonglai and Phaneng in Ledo-Margherita area in Tinsukia district. Their biggest village is the Namphake village of the Dibrugarh District. Throughout history it has been the concern of all the ethnic groups to maintain their ethnicity irrespective of the globalization which has affected each and every community. Irrespective of modernization peeping in each and every household, it has been observed that the Tai-Phake community has been able to preserve its ethnicity. This paper aims to explore the Tai-Phake tribe of the Namphake village of Dibrugarh district and how ethnicity has been preserved by the Tai-Phake's of this village with respect of various problems.

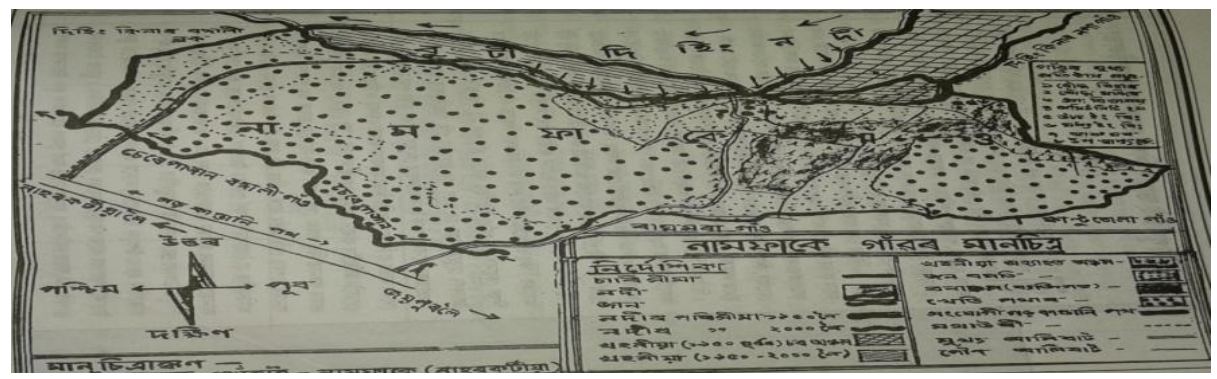

Fig.1.1. Map of Namphake village 


\subsection{Objectives:}

The main objectives of the present work are to study the -

- The socio-economic structure of the people of the region.

- To establish a relationship between the environment and the "Tai-Phake" tribe.

\section{2 . Methodology :}

\subsubsection{Selection of the topic:-}

The present work has been conducted on the Tai Phake people living in Namphake village, situated at a distance of about $3 \mathrm{kms}$ from the Naharkatiya town of Dibrugarh district of Assam in the North-East India. It is a beautiful place with a long history and holds an important place in the ethnic map of the North-East India. It is a lesser known tribe of Assam. The study has been based on mainly field work and personal observations.

\subsubsection{Collection of Data:-}

For proper understanding of a place or about an aspect some methods are essential. There are several methods to study about the earth's surface. Due to shortage of time and manpower, the methods applied for the present work are Observation method and Primary Data collection method and Secondary Data Collection method. To collect data about the Tai Phake people of Namphake village and to study its impact on the environment the following methods are used:-

- Observation Method- As a Geography student to collect data about the place i.e. Namphake and to study its impact, I have observed each spot for some time and also observed properly the whole Namphake village. By minute observation of the places and their physical and cultural elements, I have tried to visualize the direct and indirect relationship between man and environment.

- Primary Data Collection- During the visit to the place information were collected from the local people. A set of survey schedule was prepared and questions were asked to the people and recorded the information. Besides this, from the Gaon Panchayat of the village I have also acquired information during field survey.

- Secondary Data collection- For the present work we have collected secondary data about the place from magazines, books and internet. The secondary data helped a lot to understand about the place and to have a better view on the people.

\subsubsection{Data process and analysis:-}

The data after collection has to be processed and analyzed in accordance with the outline laid down for the purpose at the time of developing the search plan. In the present study, the primary data collected through the survey were processed by using cartographic and statistical technique. With the help of graph, tables etc. The variable was found out in the form of information. With the computation of data, interpretation and analysis is been made, compared between the decadal years in respect of change in literacy, population growth etc.

\section{CULTURE, TRADITION AND THE PEOPLE OF NAMPHAKE VILLAGE}

\subsection{Demographic and Employment Structure:}

Namphake village is the largest habitat of the Tai- Phake people. There are about 9 villages in North- East India, which is endowed with Tai- Phake Population. Among them Nam- Phake has about 60 households. And the total Population presently living is found to be 290 .

There has been a sincere effort to collect the name of the head of the family, there number of members, and to find out how they earn their living.

Table- 2.1.

\begin{tabular}{|l|l|l|l|l|}
\hline Household & $\begin{array}{l}\text { Head of the } \\
\text { family }\end{array}$ & Members & Occupation \\
\cline { 3 - 5 } & & Services & $\begin{array}{l}\text { Agriculture } \\
\text { Sector }\end{array}$ \\
\hline 1 & Thai Khing & 3 & 0 & 2 \\
\hline 2 & Nokufock Kyank & 4 & 1 & 2 \\
\hline 3 & Ithan & 2 & & \\
\hline
\end{tabular}


Social Framework of Ecology: Representation of Nature

\begin{tabular}{|c|c|c|c|c|}
\hline 4 & Hailetthon & 6 & & 5 \\
\hline 5 & Virotnet & 5 & 1 & 2 \\
\hline 6 & Saffae & 4 & & 4 \\
\hline 7 & Sam Saing & 6 & 4 & 1 \\
\hline 8 & Aishang Mang & 5 & 1 & 2 \\
\hline 9 & Aijan Thon & 4 & 1 & 3 \\
\hline 10 & Shai Shoi & 4 & 1 & 2 \\
\hline 11 & Shan Thang & 2 & & 2 \\
\hline 12 & Am Sao & 6 & 4 & 1 \\
\hline 13 & Shan won Thon & 5 & 0 & 5 \\
\hline 14 & Aycon & 4 & & 3 \\
\hline 15 & Ngisha Ngon & 5 & 1 & 3 \\
\hline 16 & Samngyan & 10 & 4 & 5 \\
\hline 17 & Samsa & 10 & 4 & 5 \\
\hline 18 & Nokling & 4 & 1 & 3 \\
\hline 19 & Ngikya & 2 & & 2 \\
\hline 20 & Ngihonkum & 6 & 2 & 3 \\
\hline 21 & Sai Myat Chee & 5 & 1 & 2 \\
\hline 22 & Ngimyating & 3 & 1 & 1 \\
\hline 23 & Choulin & 4 & 2 & 2 \\
\hline 24 & Sham Ngon & 5 & & 1 \\
\hline 25 & Chainython & 5 & 3 & 1 \\
\hline 26 & Aiwan Ngun & 10 & 1 & 3 \\
\hline 27 & Aijeken & 10 & 3 & 5 \\
\hline 28 & Samlun & 4 & & 4 \\
\hline 29 & E. Noyin & 3 & 1 & 2 \\
\hline 30 & Ngitankhom & 4 & 1 & 3 \\
\hline 31 & Shammgwon & 4 & 1 & 2 \\
\hline 32 & Aijenta & 10 & 2 & 6 \\
\hline 33 & Shawing to & 4 & 2 & 2 \\
\hline 34 & Ngisu Kham & 5 & 1 & 4 \\
\hline 35 & Auchauken & 4 & 1 & 3 \\
\hline 36 & Nginoije & 13 & 4 & 9 \\
\hline 37 & Amne & 7 & & 5 \\
\hline 38 & Tisas & 4 & 1 & 2 \\
\hline 39 & Lyepe Kheng & 3 & 1 & 2 \\
\hline 41 & Nakno & 4 & 1 & 2 \\
\hline 42 & Chansoi Thon & 3 & & 3 \\
\hline 43 & Champhongsa & 5 & & 5 \\
\hline 44 & Aikya & 4 & 1 & 2 \\
\hline 45 & Aaimthon & 2 & & 2 \\
\hline 46 & Chamkhing & 3 & 1 & 2 \\
\hline 47 & Nginam & 3 & & 3 \\
\hline 48 & Chaimonpheo & 7 & & 3 \\
\hline 49 & Aim Thon & 4 & 1 & 3 \\
\hline 50 & Ngikenthi & 5 & & 2 \\
\hline 51 & Aikenjing & 6 & & 3 \\
\hline 52 & Oxgseng & 4 & & 2 \\
\hline 53 & Ngiwon Kham & 4 & & 1 \\
\hline 54 & Yolokhy & 1 & & 1 \\
\hline 55 & Aijo & 6 & & 3 \\
\hline 56 & E. Wa & 1 & & 1 \\
\hline 57 & Aiming & 8 & & 6 \\
\hline
\end{tabular}




\begin{tabular}{|l|l|l|l|l|}
\hline 58 & Ngijet & 3 & 1 & 1 \\
\hline 59 & Chamkei & 8 & & 5 \\
\hline 60 & Chaijoi & 7 & 1 & 5 \\
\hline 61 & Aimjat Kham & 4 & & 4 \\
\hline Total & & 290 & 53 & 166 \\
\hline
\end{tabular}

Source- Ngipethon Gohain, Research Assistant, Centre for Studies in Language.( Dibrugarh University)

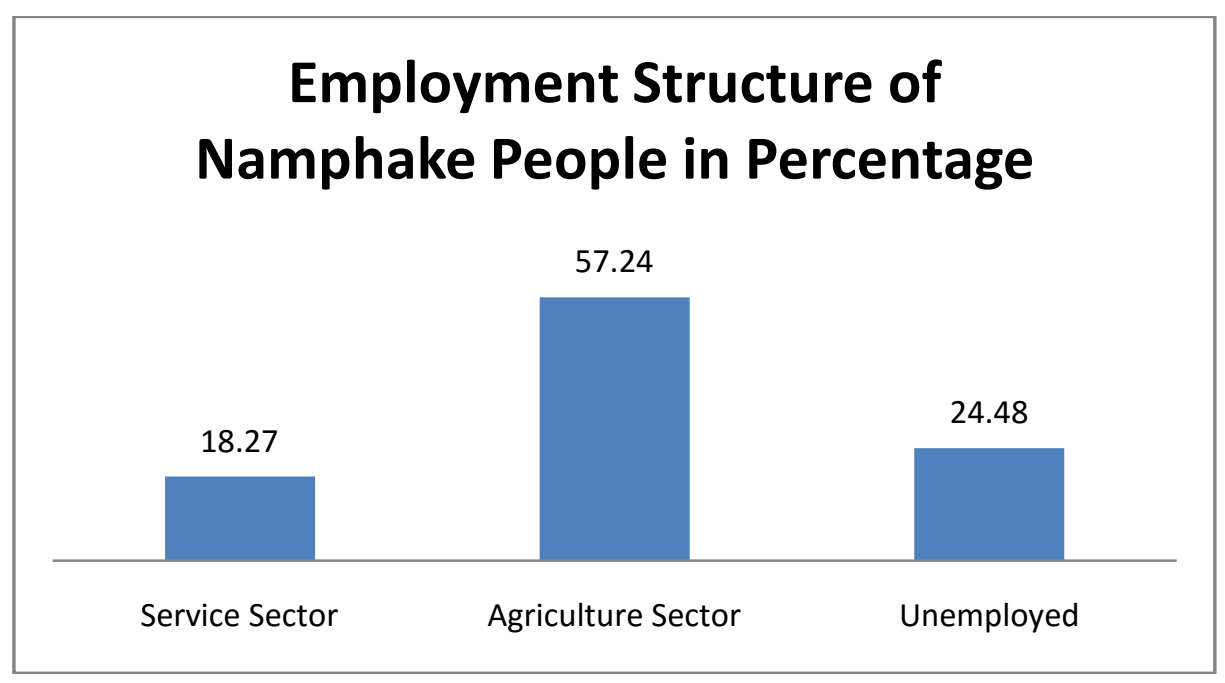

Fig.2.1. Employment structure of Namphake people

The above data reveals a very expected picture of the economic activities of the Namphake People. Not much of the people are engaged in service sector, only a mere $18 \%$ of the people are involved in the Sector. On the other hand every household are directly or indirectly are involved in Agriculture part. About $57 \%$ of the people are engaged in agriculture sector. It was also found out that about $24.48 \%$ of the total population are unemployed.

\subsection{Culture and Tradition:}

\subsubsection{Family:-}

The Tai-Phake's mostly live in nuclear families as they believe that harmony and understanding among family members can be maintained in this type of a family system. Patriarchal family system is followed and the son inherits his father's property. However, in case of a spinster, the daughter is also given a share of the property. Married girls are not given a share of the father's property. The data shows that as many as $80 \%$ of the sample households live in nuclear families. As soon as the son gets married, he shifts to another house to set up his own household. Including parents, the average family size is about 5 to 6 members. In spite of living in nuclear families, these people have preserved their culture.

\subsubsection{Dressing:-}

There is at least one handloom in every household and girls in spite of attending school or college are taught to weave their traditional dress. The Tai Phake women wear colorful dresses woven by them. Their outfit consists of an ankle-long skirt (Chin), a blouse open at the front (Nang Wat) and fastened around the armpits and a girdle (Chai Chin) to tighten the skirt around the waist. The female child wears a skirt (Chin) and a blouse. A white turban (Phahu) is worn by the women folk on individual preference. The colours of their dresses are expressive of their ages. The girls wear white sarongs; women stripped red, yellow and green sarongs and old women deep purple and blue sarongs with stripes. The men wear lungis known as phanoot, a kurta, and a folded chadar. According to the village headman, wearing the traditional dress in the village is compulsory. 


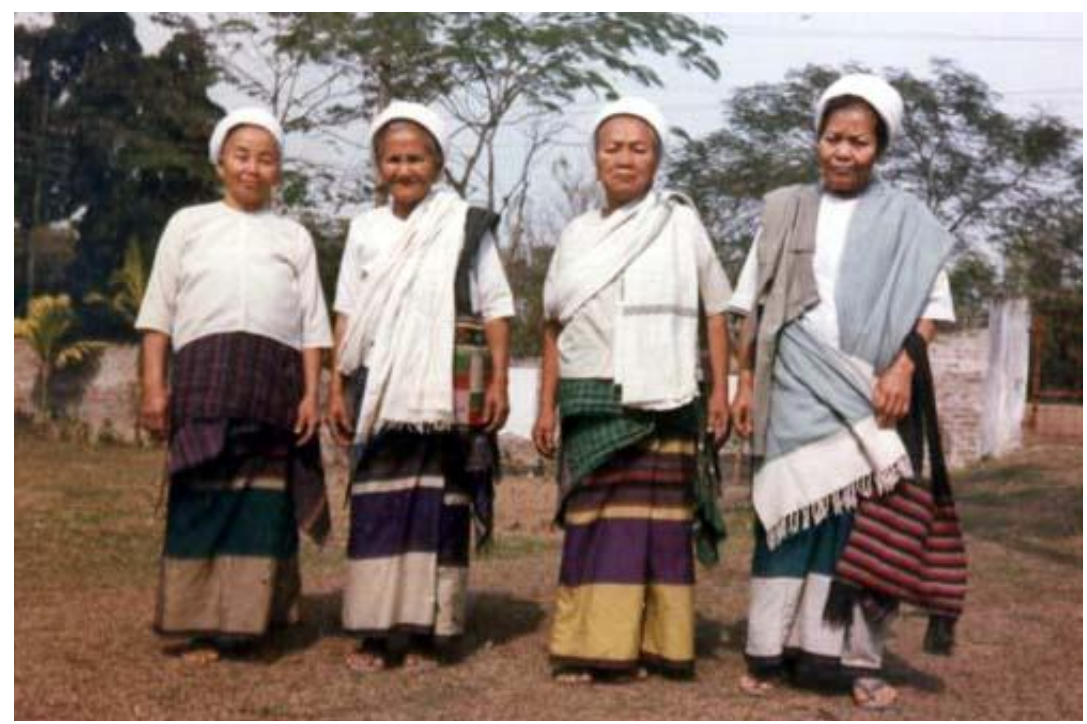

Fig. 2.2. Dress

\subsubsection{Religion:-}

The Tai-Phake community follows Buddhism. They have a Buddhist monastery in their village known as Baapsung" in their language. All the people of the village strictly follow all regulations of their religion. The Buddhist monastery at Namphake village was established in 1850. The monastery has mosaic and tiled floors. The head priest of the Namphake Buddhist temple is known as "Vante". The affairs of the monastery are run by the monks with active cooperation of the people. The people provide food and clothes to the monks.

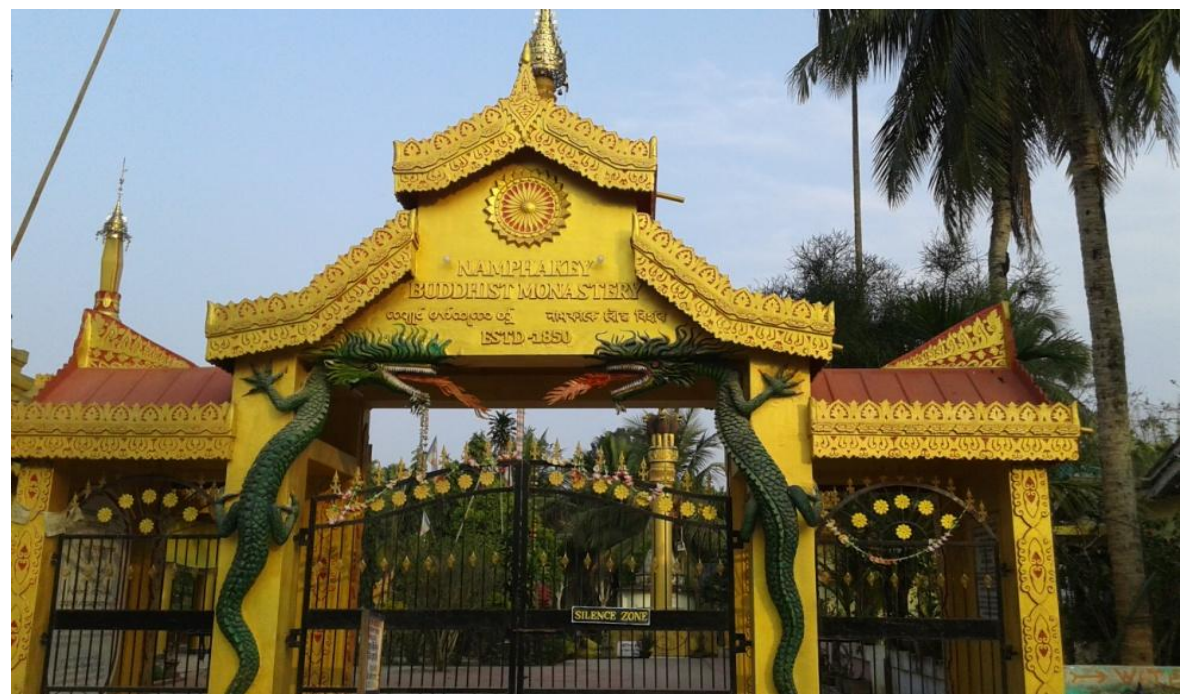

Fig.2.3. Buddhist monastery at Namphake

\subsubsection{Festivals:-}

Some of the important religious festivals of the Tai-Phake community are as follows:-

- Poi Sang Ken or Pani Bihu- The Tai-Phake calendar starts with a new year from the first day of the festival and it is celebrated for the following three days. During this festival, the villagers wash the idol of the Buddha and play with water.

- Buddha Purnima- This is celebrated after Poi Sang Ken on full moon day. 
- Barsha Bash- During this festival, the Buddhist monk undertakes fast for three months from the full moon of "ahar" to the full moon of "ahin".

- Poi Akwa- This is a festival where the Buddhist monks gather in a particular place and pray to forgive them for their sins.

- Poi Ma ko Chum- Another festival of the Tai-Phake is the 'Pai Ma Ko Chum' festival. This festival is celebrated in the month of February, fire is set on known as "mejis" on the river bank and everyone eats together in the form of picnic.

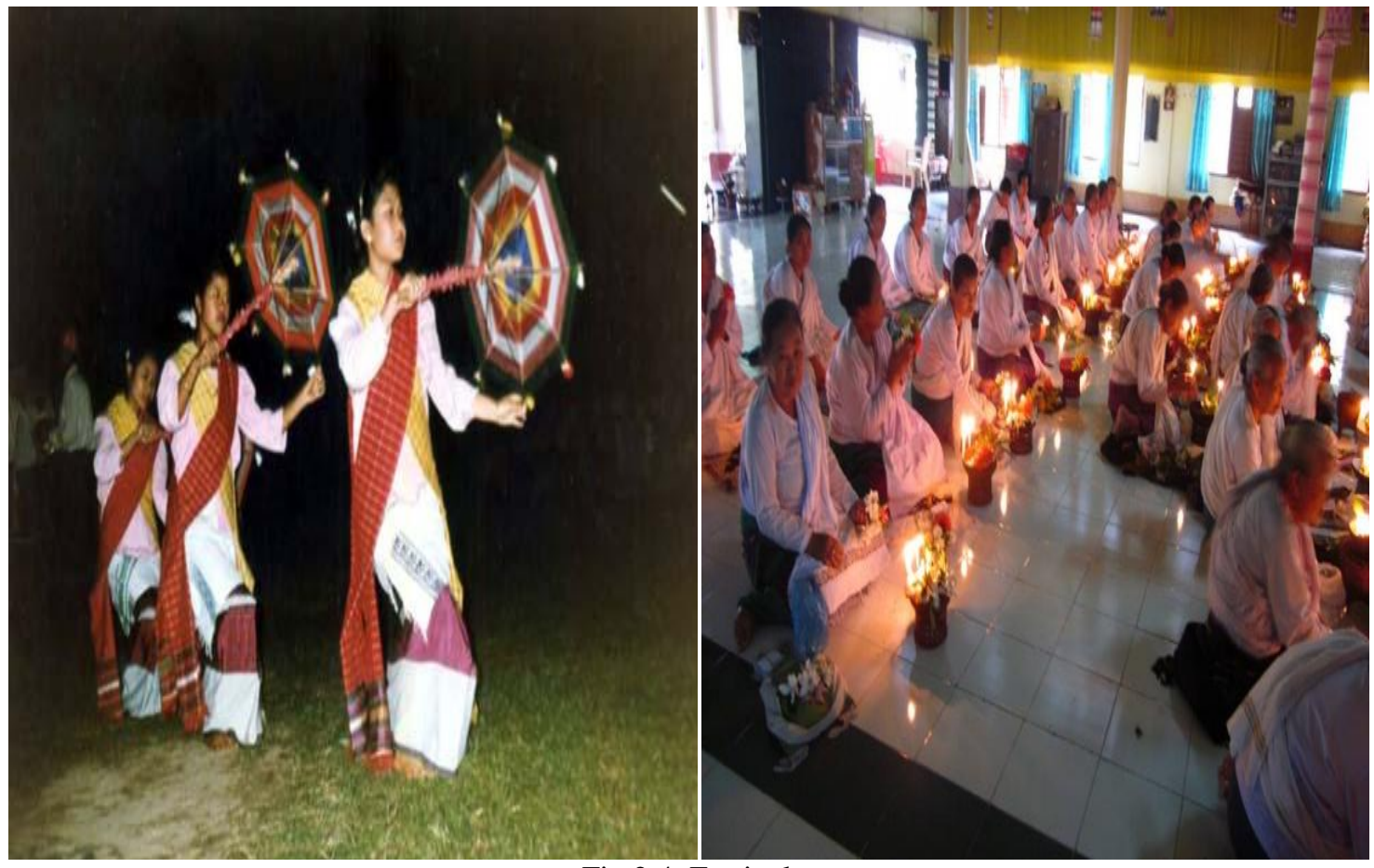

Fig.2.4. Festival

\subsubsection{Livelihood:-}

The Tai-Phake people of the Namphake village are generally engaged in primary activities. $80 \%$ of the population is engaged in agriculture. They grow rice, wheat and other crops and also grow various vegetables according to season. They grow potatoes in huge quantities. Throw selling various types of vegetables many people of this village are able to generate little bit of income. Mainly those who are engaged in rice cultivation they not only grow rice for their own subsistence for the entire year but also generate income by selling some proportion of that cultivation. Very little population of the village is engaged in secondary and tertiary activities.

\subsubsection{Food Habits:-}

Though the Tai Phake's are not restricted to any kind of food, rice is their staple. Most of their food is stir fried and they also prefer boiled vegetables, grilled meat and fish. They also prepared Pa som (sour fish), sour bamboo shoot, dried fish, dried meat, and fish wrapped in banana leaves, all put under fire ashes to be cooked. 


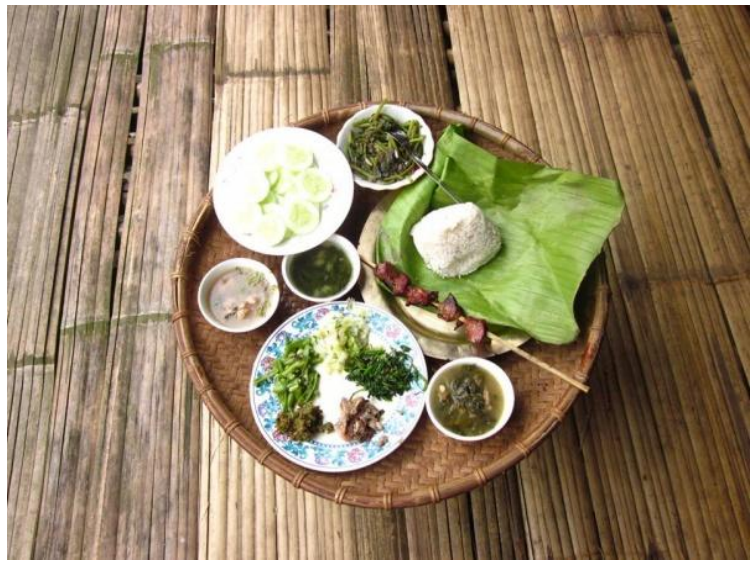

Fig.2.5.Food

\subsubsection{Approach to the technology-}

To study the relationship between technology and the people of Tai- Phake, we have collected few data's regarding various aspects, such as housing pattern, travelling methods and farming techniques.

- Housing Pattern: Every house in the Namphake Village are very close to the nature. They are made from bamboo and by mixing mud and cow dung. These houses are known as "The Chang Ghar". There are about 60 houses and every house are Chang Ghar.

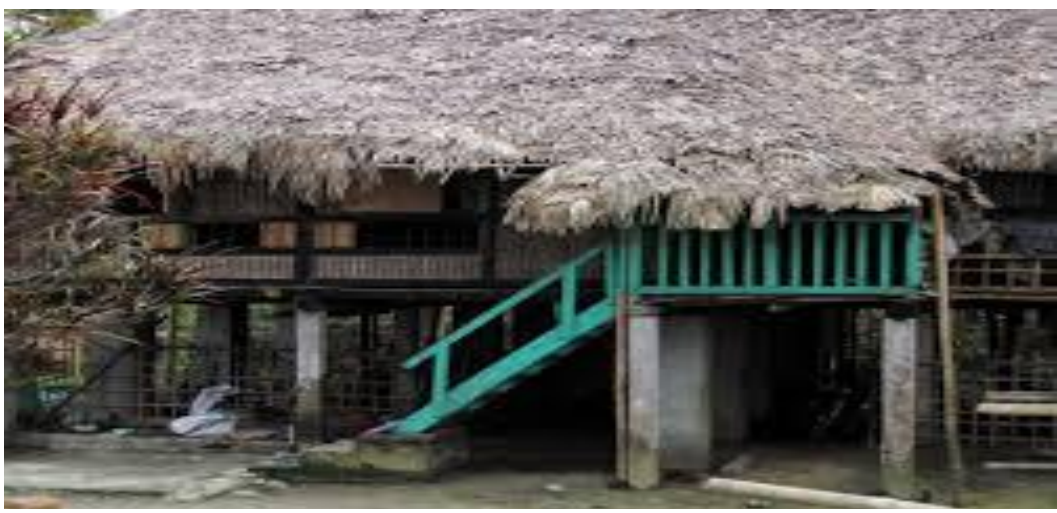

Fig.2.6.Chang Ghar

- Travelling Methods: If we look at the vehicles that they use in daily lives are commonly cycles and the motor cycles. There are about 8 cars and 45 motor cycles.

- Farming Techniques: The farming techniques are quite improved in this village. There are 9 power tillers and 3 tractors which are used by almost $67 \%$ of the households to till their land for farming. And traditional methods of farming are done by only 20 households.

\section{- Reflection of the above data:}

The people of the Namphake village are seemed to use technology but they are also maintaining a cordial relationship with nature. This can be felt when we look at their houses which is made up of mainly the raw materials found in the nature and every house are being electrified.

\subsection{Relation between the People of Namphake village and the Natural Environment:}

The people of the Namphake village maintain a strong relationship with their surrounding natural environment. The environment influence their daily life a lot including eating habits, living conditions etc. This population group basically depends on the environment for their habitation and subsistence. A close association with local ecologies and environments and a dependence on nature play a major role in shaping their culture. The relationship can be understood from the following:- 


\subsubsection{Plant : Sources of Subsistence and Medicine: -}

The plants form a major food resource for the Tai-Phake people of the village. These food resources contain high nutritional and medicinal value. There are several edible shoots, roots, tubers, leaves, flowers, fruits and seeds present in the neighborhood, which are used as vegetables and are eaten in raw or cooked form. The longterm association of these people with the natural world of rich and diversified flora and fauna enabled them to develop an understanding of the medicinal properties of plants. In time, this knowledge was transformed into a belief system and a folklore relating to the medicinal remedies of certain diseases that have traditionally been cured with herbal materials. The Tai-Phake peoples have been utilizing many of the plant resources for the cure of a large number of diseases for ages.

Some of the medicinal plants grown and used by the Tai-Phake tribe of the Namphake village are:-

\section{- Laajkosi-}

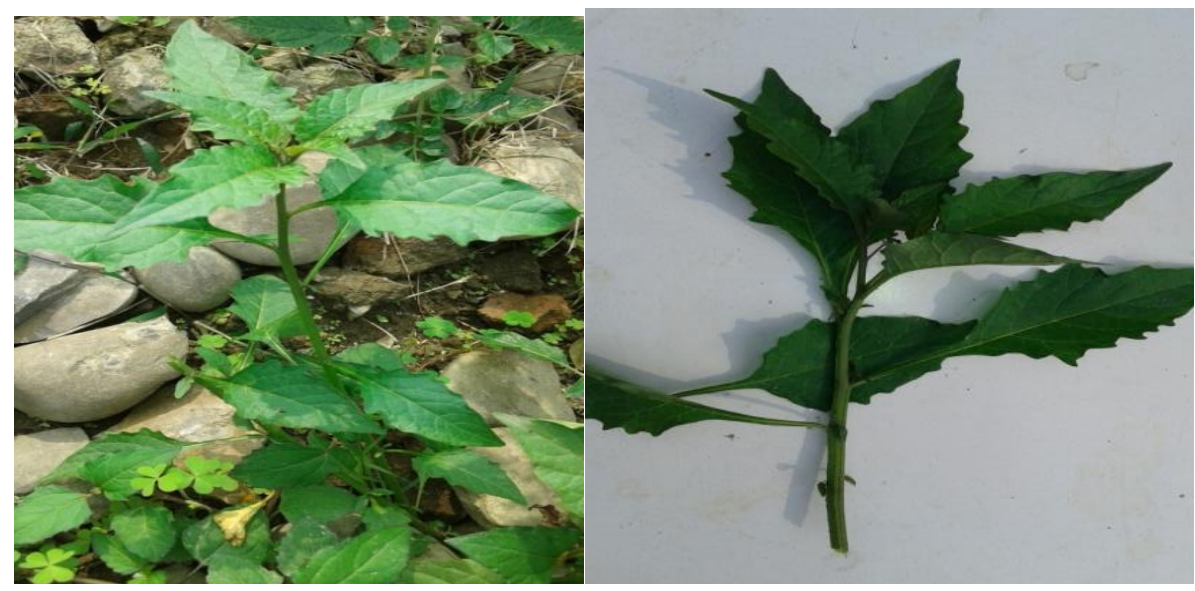

Fig.2.7. .Laajkosi

Gastric is a common problem nowadays. This plant is used by the tribe to solve gastric related problems.

- Nephaphu:-

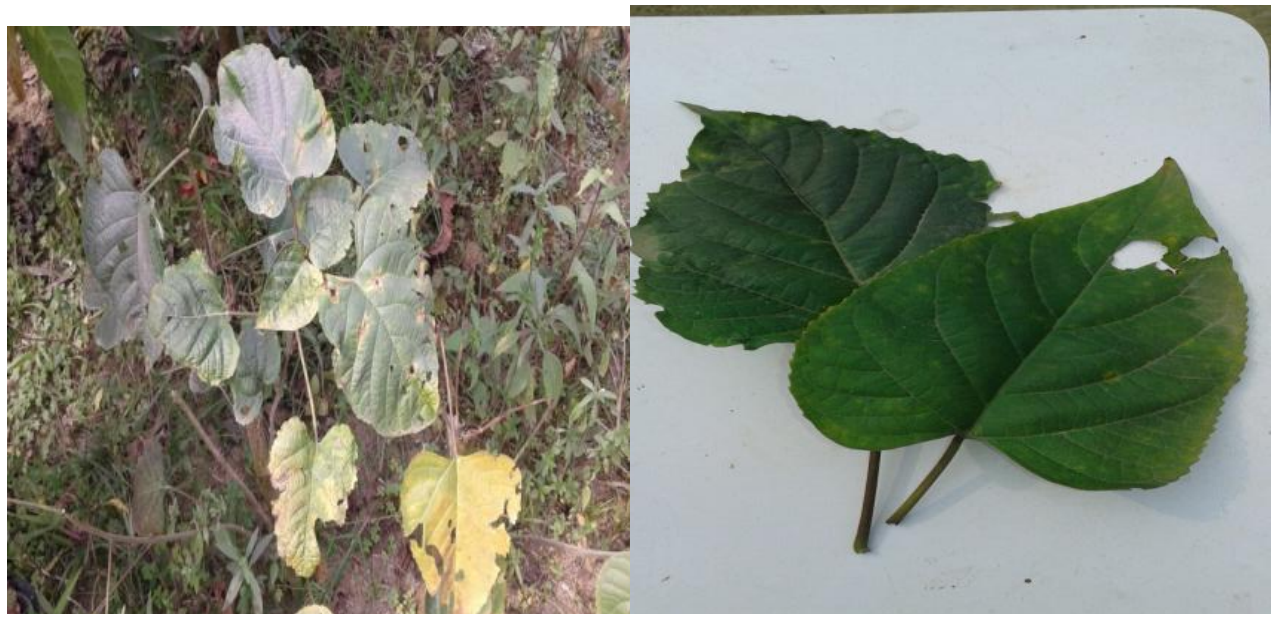

Fig.2.8..Nephaphu

This plant is often used to treat the problem of high-pressure.

- Titakosi:- 

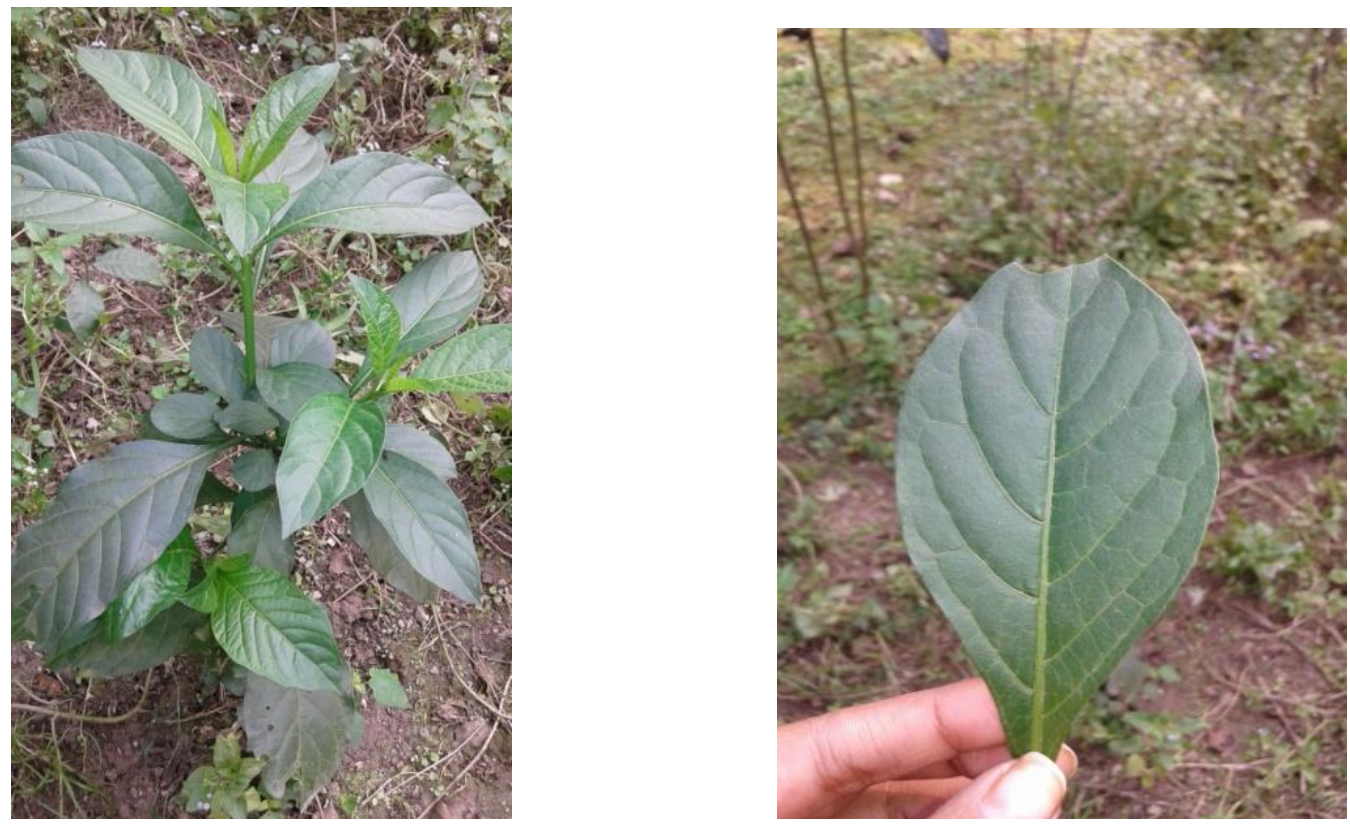

Fig.2.9.Titakosi

This plant is used to solve the problem of cough.

\section{- Pinitmen:-}

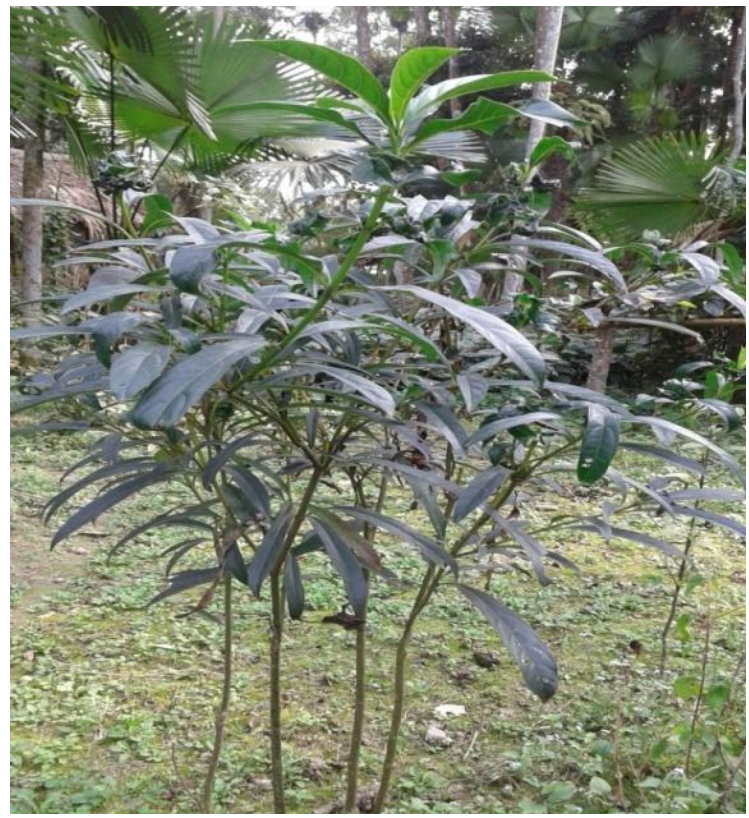

Fig.2.10.

This plant is used as a herb.

\subsubsection{Animal husbandry:-}

The Tai-Phake people practice animal husbandry and raise livestock. Animal husbandry forms a fundamental part of their life. They rear different species of animals such as cattle, cows, buffalo, goat, pigs, and poultry for the consumption of meat or milk. Cows and buffalo are also used for ploughing and provide manure. An abundance of natural fodder resources like leaves, grass and shrubs is used for grazing. Small grasslands nearby 
provide grazing land, and the availability of grazing areas is a positive factor for the growth of animal husbandry in this region.

\subsubsection{Agriculture:-}

Agriculture is an important aspect of the people of the Namphake village. A strong influence of the environment can be seen in the agricultural practices of the village. Each and every family of the village is associated with agricultural activities. The Tai-Phake people do the cultivation in lowland paddy field called "na"(pronounced "Naa"). Their habitation is connected with mainly paddy cultivation. As they reside near the Buridihing river and cultivation is done along the valleys of the river in order to take the facility of the irrigation to the paddy field. For the wet paddy cultivation the Tai-Phakes use the buffalo as the draught animal. The agricultural implements for rice cultivation are of various types according to the need of their use. All this agricultural implements are made through the materials available in the nearby natural environment. The agricultural implements used for tilling by buffalo are called-

1. "Thai" (Plough).

2. "Phue" (Cultivator).

3. "Moi" (leveler).

Besides wet rice the Tai-Phake's give equal attention towards cultivating other crops, such as pulses, specially the "Tho-nin" (Assamese- Mati- Mah.) They also grow different varieties of bananas particularly the Bhim-Kal and the Chini-Champa varieties. The plantation of sugarcane, particularly the stripped Maritius(Tai: ai-nang). The plantation of areca-nut and betel leaves is a must in every house.

\subsubsection{Housing Technology:-}

The Tai-Phake people of the Namphake village maintain a special type of housing technology. The housing pattern is dependent on local resources and influenced by environment, climate as well as culture and tastes. To minimize the effects of natural hazards such as earthquakes, heavy monsoons, floods which are quite common in the area, the Tai Phake community build their huts on a raised platform using timber or bamboo. Thatch is used for roofing. Mud mixed with cow dung is used as a tempering material for plastering the walls made of split bamboos or, otherwise, left as they are without any plaster. Ladders made of bamboo or wood are used for approaching the raised platform of the structure. The lower portion of the raised platform is used as a shelter for household animals such as goats and chickens. The holes made on the floor of the raised platform are used for passing wasted victuals to the animals kept under the structure.

Such houses built on raised platform, commonly known as chang ghar in Assamese. In the lowlands, the Tai Phake makes this type of house for safety reasons, since they live in the flood-prone areas of the Brahmaputra.

\subsubsection{Traditional Weaving methods:-}

- Handloom- One of the interesting shared features of the people of the Namphake village is the traditional method of weaving with hemp and cotton. The handicrafts practiced by the community are mostly a woman's job. Weaving is done with a simple loin-loom made of bamboo. Weavers use various colours derived from natural dyes from plant extracts and weave traditional designs and patterns on their looms. Traditional household weaving fulfils the requirements of each household and supports domestic economy. Womenfolk rear silkworm cocoons and then reel and spin the silk into traditional yarns. These are then woven in handlooms of a traditional nature by the back-strap method by which simple hand- carved sticks are used. All the equipment needed is made from locally available bamboo and wood. The handlooms used by the Tai- Phake community do not have treadles. The healds or heddles are raised by hand. The handlooms used by them are narrow with one treadle only. The shuttle is bigger in size. This one treadle and one heddle loom might have been developed on account of constant movement due to change of habitation place owing to constant warfare; but the family must have their required clothing's. So the shape of the general loom have been reduced to a minimum of one heddle and one treadle system and the weaving end tagged to the waist of the weaver. This loom is narrow and can weave cloth for a width upto a maximum of about fifty centimeters only. Thus the weaves long pieces and joins them.

- Dyeing- Dyeing is very essential with the art of weaving. The most essential color is the black color from which it extends to other colors. These colored yarns are very much essential for those who weave and wear stripped colored cloths. For the preparation of black color the Phake women collects "Hom" plants (Bot.: Strobilanthus Placcidifoliae). The plants are washed cleaned and put in water and kept submerged inside a big earthenware for six-seven days to get rotten. After a week, the rotten plants are squeezed and 
Social Framework of Ecology: Representation of Nature

dregs are thrown away. Then the "Hom" water is stirred constantly for about an hour daily for two-three days, then it is strained into another earthenware and the dirt sediments are removed. A little lime water is added and stirred till a lot of foam is formed. Then one or two kernel of smashed castor seeds and moved inside the foamed "Hom" water till the foam is vanished. Then the "Hom" water is kept for another twothree days. During these two-three days period, they prepare to collect good ash water. They put good kind of ash in a conical spilt bamboo strainer and then water is poured and then the strained ash water is collected in a pot adequately. Then they take some portion of the thick "Hom" water and mix it with the ash water in separate earthenware and dye the yarn to make black-yarn. This dyeing should be done three times. They dye it each time and spread it under the sun to dry. For fast color the juice of the bark of a kind of climbing vine, named "Tum-Kao" is added. To dye Muga silk into green, violet and red color, the silk is also dyed in "Hom" water first. Later it is boiled with threshed leaved of "Miit"/ "Muat" plant to obtain dazzling color. Another process is to boil Muga yarn with the pounded bark of "Maola" (Bot. Garcinia Xanthochymus, Gattferae) to obtain golden yellow color. To obtain red color a kind of plant called "KhaaiNeng" is used.

\subsection{Findings:}

\section{CONCLUSION}

\section{From Chapter -I}

A. Tai Phake people are the small ethnic group of North-East India.

B. According to chronicles the Tai- Phakes migrated from Mung- Mau and entered Assam in 1775 A.D during the reign of the Ahom King Lakshmi Singha.

C. They have settled permanently mostly on the bank of Burhi- Dihing river in the undivided Dibrugarh districts scattered in ten villages, namely, namphake, tipamphake, Borphake, Munglang, Ningkam, Phaneng, Manmo, Nonglai, Long and Lungkung.

D. Presently they live in the 9 villages of Dibrugarh and Tinsukia Districts.

\section{From Chapter- II}

A. They mostly live in the nuclear family.

B. Patriarchal family System is followed and the son inherits his father's property.

C. There is at least one Handloom in every households.

D. The Tai- Phake community follows Buddhism. They have Buddhist monastery in their village known as “ Baapsung" in their language.

E. The important religious festivals are poisang ken or pani Bihu, Buddha Purnima, Barsha bash, Poi Akwa, Poi Ma Ko chum.

F. They are mainly engaged in primary Activities. $57 \%$ of the people are engaged in primary activities.

G. They use various medicinal plants such as Nephaphu, Titakoi, etc.

H. Their culture is a mixture of modernization and traditions. They are people who are very much close to nature and apply a conservative approach towards the nature.

\subsection{Problems:}

Since the establishment of the village in the year 1850 and even after 68 years of India's independence the Namphake village is yet economically backward. As the residents of the village the people of the village has maintained their culture, language, heritage but it is sad to know that despite of such wonderful effort the village is educationally, socially and economically backward. Some of the main problems of the are :-

- Flood is one of the major problems of this village.

- Due to erosion year after year the village is losing hectares and hectares of land.

- Low level of literacy and educational backwardness.

- Natural calamities.

- Financial crisis.

- Lack of transportation facilities and communication problems.

- Lack of technology.

REFERENCES

[1] Gohain, Ngipethon, Research Assistant, Centre for Studies in Language.( Dibrugarh University). 
[2] Gohain, Aimya Khang, The Tai Biddhist Communities of Assam.

[3] Gohain, P.T., Namphake Gaon Derekho Bosoriya Jayanti aru Pai Loo Fra Mahotsav.

[4] Hazarika, Manjil, Man nad Environment in North-East India: An Ecological Perspective.

[5] Kingkham Wilaisak, (2001), A Comparative Study of Tai-Phuan, Tai-Phake and Lao-Wiang.

[6] Hailowng, Pow Aim, The Tai Phakes of Assam.

[7] Google, Internet. 